\title{
Usefulness of Levocarnitine and/or Branched-Chain Amino Acids during Invasive Treatment for Hepatocellular Carcinoma
}

\author{
Motoh IWASA ${ }^{1}$, Ryosuke Sugimoto ${ }^{1}$, Tomoaki ISHIHARA ${ }^{2}$, Noriko SEKOguchi-FujIKAWA ${ }^{3}$, \\ Kyoko YoshiKaWA ${ }^{1}$, Rumi MifujI-MoroKA ${ }^{1}$, Hideaki TANAKA ${ }^{1}$, Yoshinao KobaYASHI ${ }^{1}$, \\ Hiroshi HASEGAWA ${ }^{1}$ and Yoshiyuki TAKEI ${ }^{1}$ \\ ${ }^{1}$ Department of Gastroenterology and Hepatology, Mie University Graduate School of Medicine, \\ Tsu, Mie 514-8507, Japan \\ ${ }^{2}$ Department of Gastroenterology and Hepatology, Yokkaichi Digestive Disease Center, \\ Yokkaichi, Mie 510-1232, Japan \\ ${ }^{3}$ Department of Pharmacy, Mie University Hospital, Tsu, Mie 514-8507, Japan
}

(Received April 2, 2015)

\begin{abstract}
Summary Transarterial chemoembolization (TACE) and radiofrequency ablation (RFA) are effective treatments for hepatocellular carcinoma (HCC). However, the extent of treatment depends on hepatic functional reserve. L-Carnitine is a vitamin-like substance and several reports have described the usefulness of L-carnitine supplementation in cases of cirrhosis, with confirmed effectiveness against refractory hepatic encephalopathy. On the other hand, we have previously reported that in patients who underwent TACE or RFA, administration of branched-chain amino acids (BCAAs) pre-intervention significantly reduced inflammatory reactions. We first determined serum levels of total, free, and acyl-carnitine before and at $7 \mathrm{~d}$ after performing TACE in $10 \mathrm{HCC}$ patients. We administered levocarnitine (L-carnitine chloride, a biologically active form of carnitine) at $900 \mathrm{mg} / \mathrm{d}$ to 69 consecutive HCC patients hospitalized to undergo TACE and/or RFA, and compared changes in blood test values with those in 119 consecutive patients not administered this drug. Sixty-seven patients had a history of using BCAAs at the time of admission. We found that after $7 \mathrm{~d}$ of TACE, serum levels of total and acyl-carnitine are significantly decreased. On comparing the four groups, the carnitine+BCAA, carnitine-alone, and BCAA-alone groups showed significantly higher values for changes in $\mathrm{NH}_{3}$ when compared with the non-dosed group. The decrease in albumin (Alb) was significantly suppressed in the carnitine+BCAA and BCAAalone groups. We also conducted the same examinations in a subset of patients classified as Child-Pugh class A, and noted the same trends. Administration of levocarnitine and/ or BCAAs during invasive treatments reduced blood $\mathrm{NH}_{3}$ concentrations and suppressed decreases in Alb.
\end{abstract}

Key Words carnitine, hepatocellular carcinoma, ammonia, albumin, branched-chain amino acid

In addition to local therapies such as hepatectomy and radiofrequency ablation (RFA), hepatocellular carcinoma (HCC) can be treated using methods such as transarterial chemoembolization (TACE), systemic chemotherapy, molecularly targeted drugs, and liver transplant (1-3). However, many cases of HCC develop as a result of cirrhosis, so sufficient consideration must be given to hepatic functional reserve, in addition to the extent of the tumor when selecting treatment (1). Moreover, vital prognosis of HCC patients is affected by both tumor factors and hepatic functional reserve $(4,5)$, so preserving liver function represents an important challenge during treatment. Hepatic functional reserve can be improved through abstinence in cases of alcoholic cirrhosis and through administration of nucleic acid analogs in cases of type B cirrhosis. However, at present, liver function is difficult to improve in cirrhosis caused

E-mail: motoh@clin.medic.mie-u.ac.jp by the hepatitis $\mathrm{C}$ virus or nonalcoholic steatohepatitis. L-Carnitine is a vitamin-like substance involved in lipid metabolism. When carnitine levels are deficient, utilization of fatty acids is impaired and a wide range of symptoms develop, such as hepatic encephalopathy and hyperammonemia associated with various organ dysfunctions, hypoketotic hypoglycemia, muscular weakness, cardiomyopathy, and heart failure (6). Endogenous carnitine is mainly synthesized in the liver, making cirrhotic patients more susceptible to carnitine deficiency (7). Several reports have described the usefulness of L-carnitine supplementation in cases of cirrhosis, with confirmed effectiveness against refractory hepatic encephalopathy and cramps $(8,9)$; however, the relationship between carnitine supplementation and intervention for HCC remains unknown. Furthermore, changes in blood levels of carnitine after invasive treatments for HCC have not been evaluated. In addition to these clinical effects, carnitine reportedly retains mito- 
chondrial function and has an inhibitory effect on oxidative stress $(10,11)$.

Long-term supplementation with branched-chain amino acids (BCAAs) is associated with prolonged survival and decreased frequency of HCC development in patients with liver cirrhosis (12). D'Antona et al. recently showed that a mixture of BCAAs increased the average lifespan of middle-aged mice, and this result was associated with upregulation of genes for the reactive oxygen species (ROS) defense system and reduced ROS production in the cardiac and skeletal muscle of mice (13). Moreover, we previously reported that in patients who underwent TACE or RFA, administration of BCAAs pre-intervention significantly suppressed the development of post-intervention hypoalbuminemia and reduced inflammatory reactions during the subsequent clinical course (14). However, changes in blood levels of $\mathrm{NH}_{3}$ after invasive treatments for $\mathrm{HCC}$ have not been evaluated.

We therefore investigated the effects of levocarnitine (L-carnitine chloride, a biologically active form of carnitine) and/or BCAAs administered to patients undergoing TACE and/or RFA on laboratory test values, with a focus on organ-protective effects.

\section{MATERIALS AND METHODS}

First, we determined serum levels of total, free, and acyl-carnitine before and at $7 \mathrm{~d}$ after performing TACE in 10 HCC patients using the enzymatic method.

We orally administered levocarnitine chloride (Otsuka Pharmaceutical, Tokyo, Japan) at $900 \mathrm{mg} / \mathrm{d}$ (in 3 divided doses daily) to 69 consecutive HCC patients hospitalized for the purpose of undergoing TACE, RFA, or transcatheter arterial infusion (TAI) chemotherapy at Mie University Hospital or Yokkaichi Digestive Disease Center between January and May 2014. All patients were administered carnitine from admission to discharge. All patients had cirrhosis, which was diagnosed based on blood test values, imaging tests including ultrasonography and computed tomography, presence of esophageal varices, and liver histology. Changes in blood test values $\left(\mathrm{NH}_{3}\right.$, albumin [Alb], and total BCAAs to tyrosine molar ratio [BTR]) were observed on admission and at discharge. We then measured serum alanine aminotransferase (ALT) concentration before performing TACE and/or RFA and at 2, 5, and $7 \mathrm{~d}$ after these procedures. We also included 119 consecutive HCC patients hospitalized for the same procedures between January and December 2013 and between September and November 2014 who were not administered carnitine, as a control group, and compared blood test values with the carnitine group. Sixty-seven patients had a history of using BCAAs for $\geq 30 \mathrm{~d}$ at the time of admission. BCAAs used included BCAA granules orally (isoleucine $2,856 \mathrm{mg} / \mathrm{d}$, leucine $5,712 \mathrm{mg} / \mathrm{d}$, valine $3,432 \mathrm{mg} / \mathrm{d}$, in 3 divided doses daily; Ajinomoto Pharmaceuticals, Tokyo, Japan; $n=58$ ) or enteral BCAA-enriched nutrient mixtures for liver failure (isoleucine $3,846 \mathrm{mg} / \mathrm{d}$, leucine $4,074 \mathrm{mg} / \mathrm{d}$, valine $3,204 \mathrm{mg} / \mathrm{d}$, in 2 divided doses daily; Otsuka Pharmaceutical; $n=9$ ). These are the

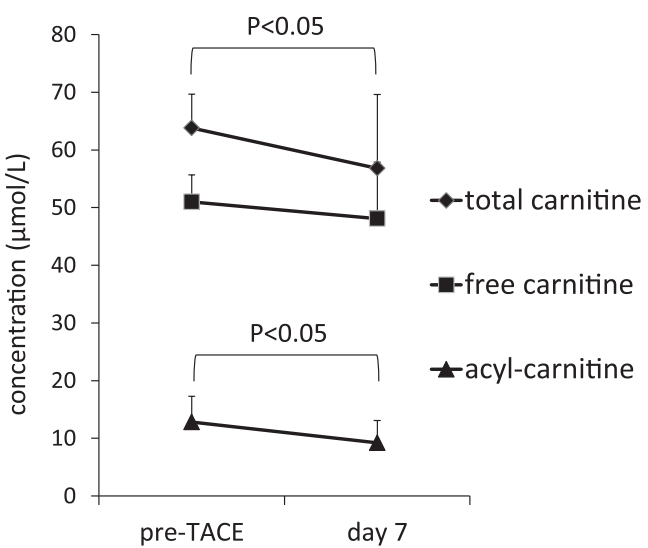

Fig. 1. Chronological changes in serum carnitine levels $(n=10)$. Total and acyl-carnitine levels were 63.8 \pm 5.9 and $12.8 \pm 4.5 \mu \mathrm{mol} / \mathrm{L}$, respectively, before TACE, and decreased significantly to $56.8 \pm 12.8 \mu \mathrm{mol} / \mathrm{L}$ and $9.2 \pm 3.9 \mu \mathrm{mol} / \mathrm{L}$, respectively $(p<0.05)$, on post-TACE day 7 . Free carnitine did not change $(51.0 \pm 4.7 \mu \mathrm{mol} / \mathrm{L}$ before vs. $48.1 \pm 9.8 \mu \mathrm{mol} / \mathrm{L}$ after $)$.

standard dosages in patients with cirrhosis. All patients were classified into a group given a combination of carnitine and BCAAs $(n=31)$, a group given carnitine alone $(n=38)$, a group given BCAAs alone $(n=36)$, and a group given nothing $(n=83)$, and changes in blood test values were compared.

The treatment for HCC was RFA in cases of ChildPugh class A or B where maximum tumor diameter was $<3 \mathrm{~cm}$ and the number of tumors was $\leq 3$. TACE or TAI was selected for cases deemed unsuitable for RFA. Miriplatin $120 \mathrm{mg}$ or intra-arterial cisplatin $100 \mathrm{mg}$ were used in TAI, while TACE involved embolization using gelatin sponge after injecting a mixture of oily contrast medium $\left(\right.$ Lipiodol $^{\circledR}$ ) and an anticancer agent (miriplatin $120 \mathrm{mg}$, intra-arterial cisplatin $100 \mathrm{mg}$, or farmorubicin 10-50 mg). TACE was performed $7 \mathrm{~d}$ prior to RFA and included patients in whom the therapeutic effect was enhanced. Patients using drug-eluting beads were not included. TACE and RFA were both performed the day after admission and drugs administered before starting this study were continued without change during the observation period. The content of meals during hospitalization was specified in accordance with the guidelines issued by the Japan Society of Metabolism and Clinical Nutrition. The possibility of discharge was left to the discretion of the attending physician and was determined based on improvements in subjective and objective findings such as fever and abdominal pain, and inflammatory findings such as liver function and C-reactive protein level. This study complied with the Declaration of Helsinki and was approved by the Ethics Committee of Mie University.

Statistics. Test values are shown as means \pm standard deviation. The chi-squared test, $m \times n$ contingency tables, and Mann-Whitney $U$ test were used to independently test for differences in the two groups, while Pearson's product-moment correlation coefficient or Spearman's rank correlation coefficient was used to find 
Table 1. Subject baseline characteristics.

\begin{tabular}{|c|c|c|c|c|}
\hline & $\begin{array}{c}\text { Carnitine + BCAA } \\
\quad(n=31)\end{array}$ & $\begin{array}{l}\text { Carnitine alone } \\
\qquad(n=38)\end{array}$ & $\begin{array}{l}\text { BCAA alone } \\
\quad(n=36)\end{array}$ & $\begin{array}{l}\text { Non-dosed } \\
\quad(n=83)\end{array}$ \\
\hline Gender (M/F) & $25 / 6$ & $33 / 5$ & $23 / 13$ & $65 / 18$ \\
\hline Age $(\mathrm{y})$ & $71 \pm 8$ & $70 \pm 12$ & $70 \pm 7$ & $74 \pm 8$ \\
\hline $\mathrm{HBV} / \mathrm{HCV} /$ alcohol/NBNC/others & $5 / 18 / 1 / 6 / 1$ & $6 / 21 / 4 / 7 / 0$ & $6 / 23 / 4 / 1 / 0$ & $16 / 44 / 13 / 9 / 1$ \\
\hline $\mathrm{TAI} / \mathrm{TACE} / \mathrm{RFA} / \mathrm{TACE}+\mathrm{RFA}$ & $2 / 16 / 9 / 4$ & $1 / 25 / 8 / 4$ & $2 / 14 / 12 / 8$ & $2 / 43 / 22 / 17$ \\
\hline HCC clinical stage $(1 / 2 / 3 / 4)$ & $5 / 17 / 4 / 5$ & $6 / 13 / 11 / 8$ & $10 / 15 / 6 / 5$ & $16 / 30 / 21 / 16$ \\
\hline $\mathrm{AFP}(\mathrm{ng} / \mathrm{mL})$ & $498 \pm 1,817$ & $919 \pm 3,506$ & $111 \pm 218$ & $1,626 \pm 11,634$ \\
\hline PIVKA-II (mAU/mL) & $4,503 \pm 10,885$ & $13,733 \pm 52,591$ & $3,378 \pm 8,677$ & $2,225 \pm 13,679$ \\
\hline Child-Pugh A/B/C & $15 / 15 / 1$ & $31 / 7 / 0$ & $20 / 15 / 1$ & $71 / 12 / 0$ \\
\hline $\mathrm{NH}_{3}(\mu \mathrm{g} / \mathrm{dL})$ & $78.9 \pm 35.3$ & $61.7 \pm 33.6$ & $76.8 \pm 36.5$ & $47.4 \pm 27.1$ \\
\hline $\operatorname{Alb}(\mathrm{g} / \mathrm{dL})$ & $3.1 \pm 0.5$ & $3.7 \pm 0.6$ & $3.2 \pm 0.5$ & $3.8 \pm 0.6$ \\
\hline Duration of hospitalization (d) & $17 \pm 14$ & $14 \pm 8$ & $21 \pm 15$ & $17 \pm 8$ \\
\hline
\end{tabular}

BCAA, branched-chain amino acid; HBV, hepatitis B virus; HCV, hepatitis C virus; NBNC, non B non C; TAI, transcatheter arterial infusion; TACE, transarterial chemoembolization; RFA, radiofrequency ablation; HCC, hepatocellular carcinoma; AFP, $\alpha$-fetoprotein; PIVKA, proteins induced by vitamin K absence; Alb, albumin.

${ }^{*} p<0.05 ;{ }^{* *} p<0.01 ;{ }^{* * *} p<0.001$.

correlations between test values. The Wilcoxon signedrank test was used to compare changes in test values. The level of significance was set at $p<0.05$.

\section{RESULTS}

\section{Chronological changes in serum carnitine levels}

Serum carnitine concentration was determined in 10 HCC patients ( 8 men, 2 women; mean age, $71 \mathrm{y}$ ). Total and acyl-carnitine levels were $63.8 \pm 5.9$ and $12.8 \pm 4.5 \mu \mathrm{mol} / \mathrm{L}$, respectively, before TACE and decreased significantly to $56.8 \pm 12.8 \mu \mathrm{mol} / \mathrm{L}$ and $9.2 \pm 3.9 \mu \mathrm{mol} / \mathrm{L}$, respectively $(p<0.05)$ on postTACE day 7. Free carnitine levels did not change $(51.0 \pm 4.7 \mu \mathrm{mol} / \mathrm{L}$ before vs. $48.1 \pm 9.8 \mu \mathrm{mol} / \mathrm{L}$ after $)$ (Fig. 1).

Baseline characteristics of subjects

Subject baseline characteristics are shown in Table 1. Patients were classified into the following 4 groups: a group given a combination of carnitine and BCAAs; a group given carnitine alone; a group given BCAAs alone; and a group given nothing. There were 31,38 , 36 , and 83 patients, respectively, in each group. BCAAtreated patients had a significantly lower hepatic functional reserve and hypoalbuminemia than non-BCAAtreated patients (Table 1). We also compared groups for treatment regimen (TAI, TACE alone, RFA alone, and RFA after TACE), HCC stage (Liver Cancer Study Group of Japan), and concentrations of $\alpha$-fetoprotein and proteins induced by vitamin $\mathrm{K}$ absence-II on admission. However, there were no significant differences in any items. Duration of hospitalization was $14 \pm 8 \mathrm{~d}$ in the carnitine group and $21 \pm 15 \mathrm{~d}$ in the BCAA group, indi- cating a shorter duration in the former. Administration of levocarnitine was not interrupted or discontinued due to side effects in any patients.

Changes in plasma ammonia, serum Alb, and BTR

Plasma $\mathrm{NH}_{3}$ concentrations on admission and at discharge were $68.6 \mu \mathrm{g} / \mathrm{dL}$ and $55.3 \mu \mathrm{g} / \mathrm{dL}$, respectively, in the carnitine group and $57.9 \mu \mathrm{g} / \mathrm{dL}$ and $51.6 \mu \mathrm{g} / \mathrm{dL}$, respectively, in the control group, indicating decreases in both groups, although these were more marked in the former (Fig. 2A). On comparing the four groups, carnitine + BCAA, carnitine-alone, and BCAA-alone groups showed significantly higher values for change in $\mathrm{NH}_{3}$ (as the magnitude of decrease, from $\mathrm{NH}_{3}$ at discharge $-\mathrm{NH}_{3}$ on admission) compared with the non-dosed group ( $p<0.001, p<0.05, p<0.001$, respectively; Fig. 2B). We also found that the serum Alb concentration had decreased in both the carnitine and control groups from admission to discharge $(3.5 \mathrm{~g} / \mathrm{dL}$ and $3.0 \mathrm{~g} / \mathrm{dL}$ vs. $3.6 \mathrm{~g} / \mathrm{dL}$ and $3.1 \mathrm{~g} / \mathrm{dL}$, respectively; Fig. $3 \mathrm{~A}$ ). However, the decrease in Alb (magnitude of decrease, from Alb at discharge - Alb on admission) was significantly suppressed in the carnitine+BCAA and BCAA-alone groups when compared with the non-dosed group $(p<$ 0.05 and $p<0.01$, respectively; Fig. 3B). The same examination was performed for serum BTR, although no significant changes were observed (Supplementary Fig. $1 \mathrm{~A}$ and B).

We also conducted the same examinations in a subset of patients classified as Child-Pugh class A. The carnitine $+\mathrm{BCAA}$, carnitine-alone, and BCAA-alone groups showed significantly higher values for changes in $\mathrm{NH}_{3}$ when compared with the non-dosed group $(p<0.05$, 
A

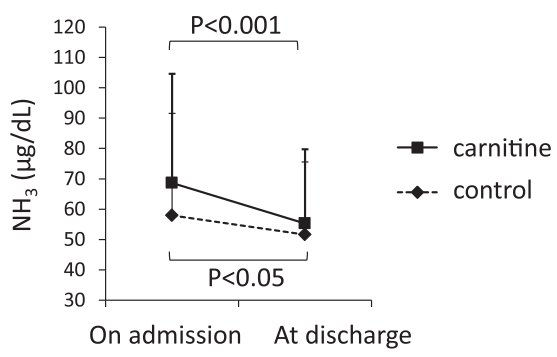

B

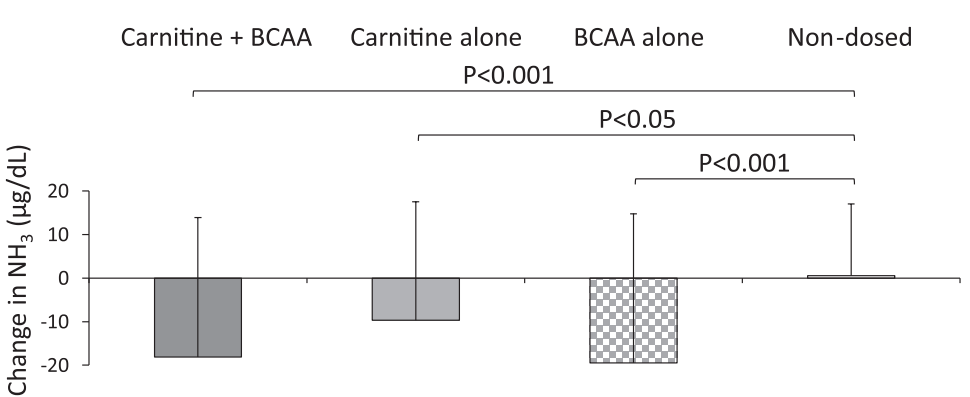

Fig. 2. Changes in plasma $\mathrm{NH}_{3}$. (A) Plasma $\mathrm{NH}_{3}$ concentrations on admission and at discharge were $68.6 \pm 36.0 \mu \mathrm{g} / \mathrm{dL}$ and $55.2 \pm 24.5 \mu \mathrm{g} / \mathrm{dL}$, respectively, in the carnitine group $(n=69)$ and $57.9 \pm 33.7 \mu \mathrm{g} / \mathrm{dL}$ and $51.6 \pm 24.0 \mu \mathrm{g} / \mathrm{dL}$, respectively, in the control group $(n=119)$, indicating decreases in both groups, although these were more marked in the former $(p<0.001$ vs. $p<0.05)$. (B) The carnitine+BCAA $(18.1 \pm 32.0 \mu \mathrm{g} / \mathrm{dL}, n=31)$, carnitine-alone $(9.7 \pm 27.2 \mu \mathrm{g} / \mathrm{dL}, n=38)$, and BCAA-alone $(19.5 \pm 34.2 \mu \mathrm{g} / \mathrm{dL}, n=36)$ groups displayed significantly higher values for changes in $\mathrm{NH}_{3}$ (decrease; $\mathrm{NH}_{3}$ at discharge $-\mathrm{NH}_{3}$ on admission), as compared with the non-dosed group $(0.6 \pm 16.5 \mu \mathrm{g} / \mathrm{dL}, n=83)$. BCAA, branched-chain amino acid.

A

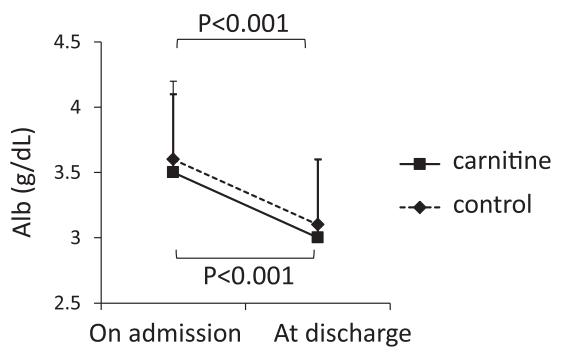

B

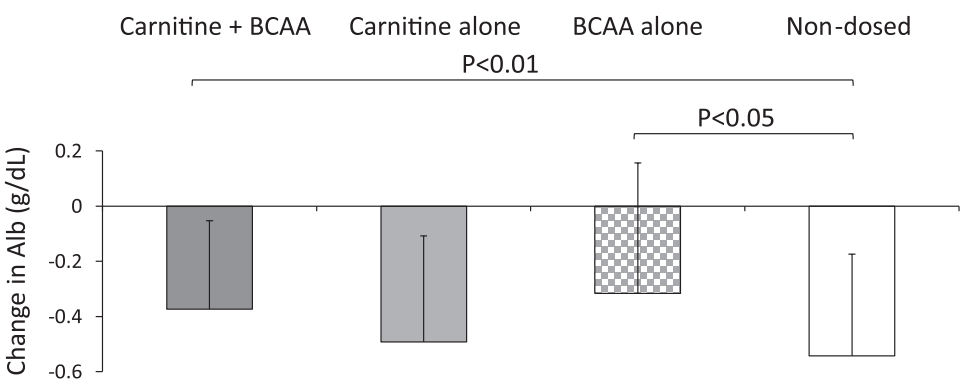

Fig. 3. Changes in serum Alb. (A) Serum Alb concentration decreased from admission to discharge in both the carnitine $(n=69)$ and control $(n=119)$ groups $(3.5 \pm 0.6 \mathrm{~g} / \mathrm{dL}$ and $3.0 \pm 0.6 \mathrm{~g} / \mathrm{dL}$ vs. $3.6 \pm 0.6 \mathrm{~g} / \mathrm{dL}$ and $3.1 \pm 0.5 \mathrm{~g} / \mathrm{dL}$, respectively). (B) The decrease in Alb was significantly suppressed in the carnitine + BCAA $(0.37 \pm 0.32 \mathrm{~g} / \mathrm{dL}, n=31)$ and BCAA-alone $(0.32 \pm 0.47 \mathrm{~g} / \mathrm{dL}, n=36)$ groups compared with the non-dosed group $(0.54 \pm 0.37 \mathrm{~g} / \mathrm{dL}, n=83)$. Alb, albumin; BCAA, branched-chain amino acid.

$p<0.05, p<0.001$, respectively; Fig. 4A). In addition, the decrease in Alb tended to be suppressed in the carnitine $+\mathrm{BCAA}$ and BCAA-alone groups when compared with the non-dosed group ( $p=0.06$ and $p=0.11$, respectively; Fig. 4B). In Child-Pugh B cirrhotic patients, the same trends were observed, but the difference was not significant (Supplementary Fig. 2A and B). The small number of cases may have affected this result.

Chronological changes in serum ALT

The change in ALT (where 0 indicates the point prior to invasive treatment) was greatest on the second postoperative day and decreased significantly on postopera- 


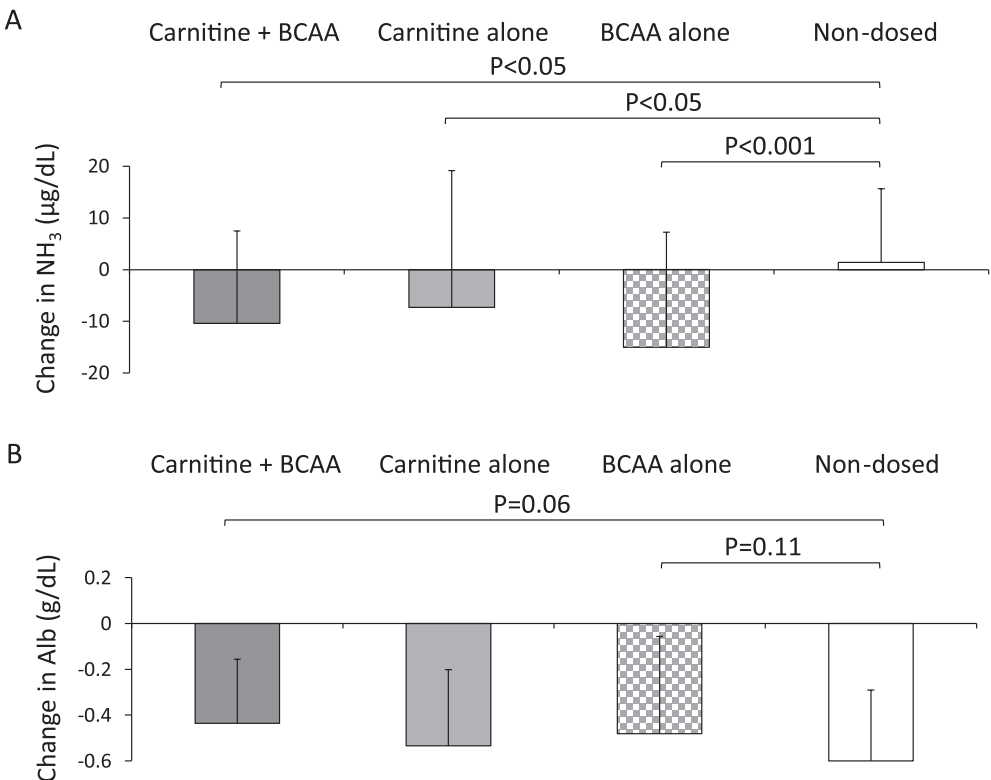

Fig. 4. Changes in blood $\mathrm{NH}_{3}$ and Alb in patients classified as Child-Pugh class A. (A) The carnitine $+\mathrm{BCAA}(10.4 \pm 17.9 \mu \mathrm{g} /$ $\mathrm{dL}, n=15)$, carnitine-alone $(7.3 \pm 26.5 \mu \mathrm{g} / \mathrm{dL}, n=31)$, and BCAA-alone $(15.1 \pm 22.3 \mu \mathrm{g} / \mathrm{dL}, n=20)$ groups displayed significantly higher values for changes in $\mathrm{NH}_{3}$ when compared with the non-dosed group $(1.4 \pm 14.3 \mu \mathrm{g} / \mathrm{dL}, n=71)$. (B) The decrease in Alb tended to be suppressed in the carnitine+BCAA $(0.44 \pm 0.28 \mathrm{~g} / \mathrm{dL}, n=15)$ and BCAA-alone $(0.48 \pm 0.42 \mathrm{~g} /$ $\mathrm{dL}, n=20)$ groups when compared with the non-dosed group $(0.60 \pm 0.31 \mathrm{~g} / \mathrm{dL}, n=71)(p=0.06$ and $p=0.11$, respectively). Alb, albumin; BCAA, branched-chain amino acid.

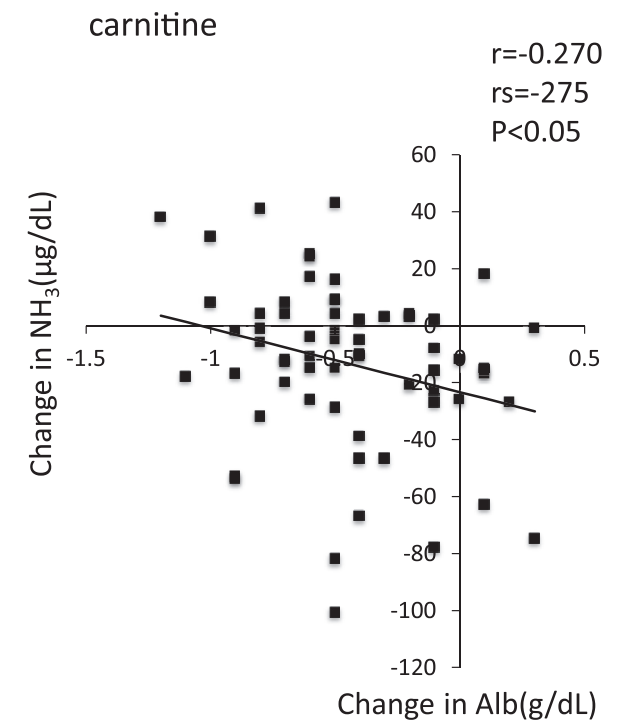

control

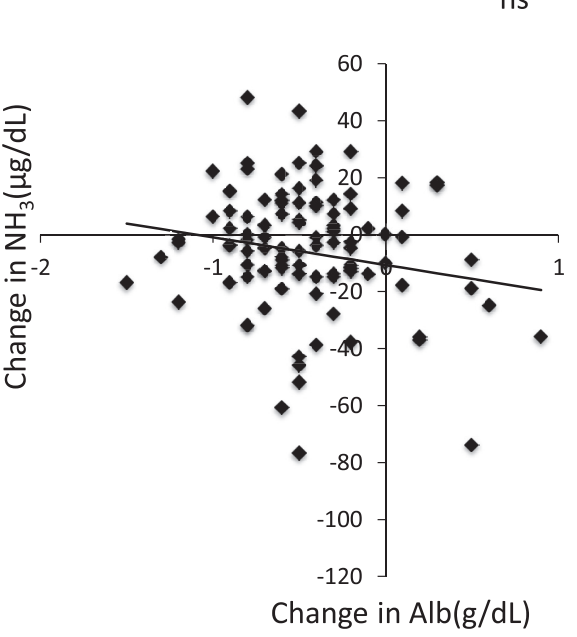

Fig. 5. Correlation between changes in $\mathrm{NH}_{3}$ and Alb. A negative correlation was observed between changes in $\mathrm{NH}_{3}$ and Alb in the carnitine group, but this correlation was not observed in the control group.

tive days 5 and 7 . No changes in ALT concentrations were seen when comparing the carnitine and control groups (Supplementary Fig. 3).

Correlation between changes in $\mathrm{NH}_{3}$ and Alb

A negative correlation was observed between changes in $\mathrm{NH}_{3}$ and Alb in the carnitine group and an association was observed between the changes (improvement) in both (Fig. 5). This type of correlation was not observed in the control group (Fig. 5).

\section{DISCUSSION}

We observed a decrease in plasma $\mathrm{NH}_{3}$ levels within a relatively short treatment period with levocarnitine during invasive treatments including TACE and/or RFA. Several reports have already cited the $\mathrm{NH}_{3}$-lowering effects of carnitine in cirrhosis $(8,15,16)$, and levocarnitine is being adopted as a new therapeutic option for cases of cirrhosis accompanied by refractory hepatic encephalopathy that prove resistant to synthetic disaccharides and rifaximin. Carnitine is also used to treat 
hyperammonemia when using valproic acid and antimicrobials containing a pivoxil group (17). The mechanisms responsible for improvement in $\mathrm{NH}_{3}$ are unclear, although $\mathrm{NH}_{3}$-processing ability in the urea cycle is thought to be enhanced by increases in $\mathrm{N}$-acetylglutamate, while energy metabolism is improved by increases in acetyl coenzyme $\mathrm{A}(\mathrm{CoA})$ and optimization of the acetyl CoA-to-free CoA ratio $(18,19)$.

The present study also confirmed the $\mathrm{NH}_{3}$-lowering effects of administering BCAAs. Although the $\mathrm{NH}_{3}$-lowering effects of BCAA have not been determined, BCAAs may facilitate ammonia metabolism in the glutamate/ glutamine pathway by functioning as a precursor to $\alpha$-ketoglutarate in this pathway. Carnitine is essential for the function of the tricarboxylic acid cycle, but because BCAAs are also precursors to $\alpha$-ketoglutarate, they are needed to retain function $(20,21)$. Although BCAAs had already been administered for more than 30 d, blood $\mathrm{NH}_{3}$ decreased further during hospitalization. Generally, we assume that plasma ammonia levels improve during hospitalization due to optimization of protein intake. However, disturbance of ammonia metabolism due to insufficiency of BCAAs during invasive treatments might suppress the ammonia-lowering effects, particularly in non-BCAA-treated patients.

A new finding from the present study is that the decrease in Alb due to invasive treatment can be suppressed with levocarnitine and/or BCAA therapy. Carnitine and BCAAs have been identified as having organprotective effects, such as anti-oxidative stress and anti-inflammatory effects, based on clinical cases and basic research into maintenance dialysis and tumorbearing patients $(10,11,13,14,21-23)$. The suppression of decreases in Alb during invasive treatment observed here may have been attributable to improvements in energy metabolism and organ-protective effects, among other factors. With regard to the relationship between $\mathrm{NH}_{3}$ and Alb, supplementation of carnitine may cause BCAAs used in $\mathrm{NH}_{3}$ metabolism to switch to Alb synthesis. However, this mechanism is unlikely, as the dosing period for levocarnitine in this study was short and no changes were observed in BTR.

In the carnitine+BCAA and BCAA-alone groups, there appeared to be no obvious differences in the $\mathrm{NH}_{3}$ decreasing effects or in the suppression of Alb decreases. In the treatment of HCC, it may be sufficient to administer BCAAs alone. However, it has recently become possible in Japan to administer BCAAs to treat cirrhotic patients with malnutrition accompanied by hypoalbuminemia and/or hyperammonemia. Thus, it is difficult to supplement BCAAs in all patients with HCC during invasive treatment.

The present study revealed that administration of levocarnitine and/or BCAAs during invasive treatment such as TACE and RFA decreased $\mathrm{NH}_{3}$ levels in the blood, and suppressed decreases in Alb. These therapies seem very likely to prove useful in reducing the invasiveness of HCC treatment, as they can be safely applied without side effects. Since the publication of evidence that BCAAs improve the vital prognosis of cirrhotic patients, these supplements have gained wider use in routine clinical practice $(23,24)$. Further investigations are necessary to determine whether supplementing carnitine during treatment can contribute to further improvements in the prognosis of HCC patients.

\section{Conflict of interests}

There are no conflicts of interest to declare.

\section{Source of funding}

We received no external financial support.

\section{REFERENCES}

1) Hasegawa K, Kokudo N, Makuuchi M, Izumi N, Ichida T, Kudo M, Ku Y, Sakamoto M, Nakashima O, Matsui O, Matsuyama Y. 2013. Comparison of resection and ablation for hepatocellular carcinoma: A cohort study based on a Japanese nationwide survey. J Hepatol $\mathbf{5 8}$ : $724-729$.

2) Llovet JM, Real MI, Montana X, Planas R, Coll S, Aponte J, Ayuso C, Sala M, Muchart J, Solà R, Rodés J, Bruix J; Barcelona Liver Cancer Group. 2002. Arterial embolisation or chemoembolisation versus symptomatic treatment in patients with unresectable hepatocellular carcinoma: a randomised controlled trial. Lancet 359 : 1734-1739.

3) Llovet JM, Ricci S, Mazzaferro V, Hilgard P, Gane E, Blanc JF, de Oliveira AC, Santoro A, Raoul JL, Forner A, Schwartz M, Porta C, Zeuzem S, Bolondi L, Greten TF, Galle PR, Seitz JF, Borbath I, Häussinger D, Giannaris T, Shan M, Moscovici M, Voliotis D, Bruix J; SHARP Investigators Study Group. 2008. Sorafenib in advanced hepatocellular carcinoma. N Engl J Med 359: 378-390.

4) Takayasu K, Arii S, Kudo M, Ichida T, Matsui O, Izumi N, Matsuyama Y, Sakamoto M, Nakashima O, Ku Y, Kokudo N, Makuuchi M. 2012. Superselective transarterial chemoembolization for hepatocellular carcinoma. Validation of treatment algorithm proposed by Japanese guidelines. J Hepatol 56: 886-892.

5) Poon RT, Ng IO, Fan ST, Lai EC, Lo CM, Liu CL, Wong J. 2001. Clinicopathologic features of long-term survivors and disease-free survivors after resection of hepatocellular carcinoma: a study of a prospective cohort. J Clin Oncol 19: 3037-3044.

6) Tanphaichitr V, Leelahagul P. 1993. Carnitine metabolism and human carnitine deficiency. Nutrition 9: 246-254.

7) Krähenbühl S. 1996. Carnitine metabolism in chronic liver disease. Life Sci 59: 1579-1599.

8) Jiang Q, Jiang G, Shi KQ, Cai H, Wang YX, Zheng MH. 2013. Oral acetyl-L-carnitine treatment in hepatic encephalopathy: view of evidence-based medicine. Ann Hepatol 12: 803-809.

9) Vidot H, Carey S, Allman-Farinelli M, Shackel N. 2014. Systematic review: the treatment of muscle cramps in patients with cirrhosis. Aliment Pharmacol Ther 40: 221-232.

10) Yang SK, Xiao L, Song PA, Xu X, Liu FY, Sun L. 2014. Effect of L-carnitine therapy on patients in maintenance hemodialysis: a systematic review and meta-analysis. $J$ Nephrol 27: 317-329.

11) Gramignano G, Lusso MR, Madeddu C, Massa E, Serpe R, Deiana L, Lamonica G, Dessì M, Spiga C, Astara G, Macciò A, Mantovani G. 2006. Efficacy of l-carnitine 
administration on fatigue, nutritional status, oxidative stress, and related quality of life in 12 advanced cancer patients undergoing anticancer therapy. Nutrition 22: 136-145.

12) Marchesini G, Bianchi G, Merli M, Amodio P, Panella C, Loguercio C, Rossi Fanelli F, Abbiati R; Italian BCAA Study Group. 2003. Nutritional supplementation with branched-chain amino acids in advanced cirrhosis: a double-blind, randomized trial. Gastroenterology 124: 1792-1801.

13) D’Antona G, Ragni M, Cardile A, Tedesco L, Dossena M, Bruttini F, Caliaro F, Corsetti G, Bottinelli R, Carruba MO, Valerio A, Nisoli E. 2010. Branched-chain amino acid supplementation promotes survival and supports cardiac and skeletal muscle mitochondrial biogenesis in middle-aged mice. Cell Metab 12: 362-372.

14) Ishihara $T$, Iwasa $M$, Tanaka $H$, Kaito M, Ikoma J, Shibata T, Takei Y. 2014. Effect of branched-chain amino acids in patients receiving intervention for hepatocellular carcinoma. World J Gastroenterol 20: 2673-2680.

15) Malaguarnera M, Pistone G, Astuto M, Vecchio I, Raffaele R, Lo Giudice E, Rampello L. 2006. Effects of L-acetylcarnitine on cirrhotic patients with hepatic coma: randomized double-blind, placebo-controlled trial. Dig Dis Sci 51: 2242-2247.

16) Malaguarnera M, Vacante M, Giordano M, Pennisi G, Bella R, Rampello L, Malaguarnera M, Li Volti G, Galvano F. 2011. Oral acetyl-L-carnitine therapy reduces fatigue in overt hepatic encephalopathy: a randomized, double-blind, placebo-controlled study. Am J Clin Nutr 93: 799-808.

17) Lheureux PE, Hantson P. 2009. Carnitine in the treatment of valproic acid-induced toxicity. Clin Toxicol (Phila) 47: 101-111.

18) Horiuchi M, Kobayashi K, Tomomura M, Kuwajima M, Imamura Y, Koizumi T, Nikaido H, Hayakawa J, Saheki T. 1992. Carnitine administration to juvenile visceral steatosis mice corrects the suppressed expression of urea cycle enzymes by normalizing their transcription. J Biol Chem 267: 5032-5035.

19) Muoio DM, Noland RC, Kovalik JP, Seiler SE, Davies MN, DeBalsi KL, Ilkayeva OR, Stevens RD, Kheterpal I, Zhang J, Covington JD, Bajpeyi S, Ravussin E, Kraus W, Koves TR, Mynatt RL. 2012. Muscle-specific deletion of carnitine acetyltransferase compromises glucose tolerance and metabolic flexibility. Cell Metab 15: 764-777.

20) Malaguarnera M, Risino C, Cammalleri L, Malaguarnera L, Astuto M, Vecchio I, Rampello L. 2009. Branched chain amino acids supplemented with L-acetylcarnitine versus BCAA treatment in hepatic coma: a randomized and controlled double blind study. Eur J Gastroenterol Hepatol 21: 762-770.

21) Johansen ML, Bak LK, Schousboe A, Iversen P, Sørensen M, Keiding S, Vilstrup H, Gjedde A, Ott P, Waagepetersen HS. 2007. The metabolic role of isoleucine in detoxification of ammonia in cultured mouse neurons and astrocytes. Neurochem Int 50: 1042-1051.

22) Savica V, Santoro D, Mazzaglia G, Ciolino F, Monardo P, Calvani M, Bellinghieri G, Kopple JD. 2005. L-carnitine infusions may suppress serum C-reactive protein and improve nutritional status in maintenance hemodialysis patients. J Ren Nutr 15: 225-230.

23) Kawaguchi T, Shiraishi K, Ito T, Suzuki K, Koreeda C, Ohtake T, Iwasa M, Tokumoto Y, Endo R, Kawamura NH, Shiraki M, Habu D, Tsuruta S, Miwa Y, Kawaguchi A, Kakuma T, Sakai H, Kawada N, Hanai T, Takahashi S, Kato A, Onji M, Takei Y, Kohgo Y, Seki T, Tamano M, Katayama K, Mine T, Sata M, Moriwaki H, Suzuki K. 2014. Branched-chain amino acids prevent hepatocarcinogenesis and prolong survival of patients with cirrhosis. Clin Gastroenterol Hepatol 12: 1012-1018.

24) Moriwaki H, Shiraki M, Fukushima H, Shimizu M, Iwasa J, Naiki T, Nagaki M. 2008. Long-term outcome of branched-chain amino acid treatment in patients with liver cirrhosis. Hepatol Res 38: S102-106.

A

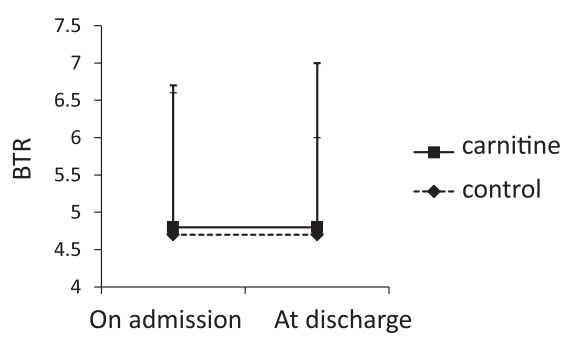

B Carnitine + BCAA Carnitine alone BCAA alone Non-dosed

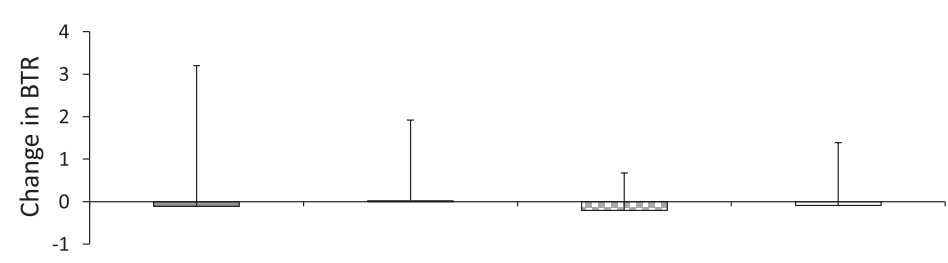

Supplementary Fig. 1. Changes in serum BTR. (A) Serum BTR in both the carnitine $(n=69)$ and control $(n=119)$ groups from admission to discharge remained unchanged (4.8 \pm 1.9 and $4.8 \pm 2.2$ vs. $4.7 \pm 1.9$ and $4.7 \pm 1.3$, respectively). (B) On comparing the four groups, no significant changes were observed $(0.11 \pm 3.32, n=31$, carnitine $+\mathrm{BCAA} ; 0.02 \pm 1.90$, $n=38$, carnitine-alone; $-0.21 \pm 0.88, n=36$, BCAA-alone; $-0.09 \pm 1.48, n=83$, non-dosed). BTR, molar ratio of total branched-chain amino acids [BCAAs] to tyrosine. 
A
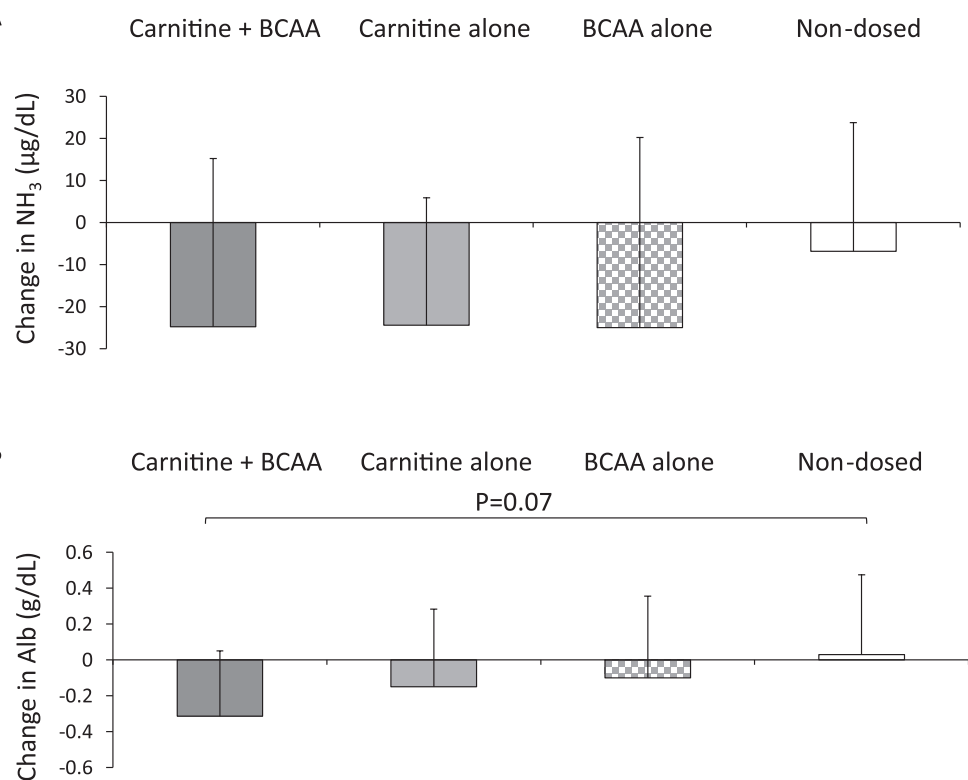

Supplementary Fig. 2. Changes in blood $\mathrm{NH}_{3}$ and Alb in patients classified as Child-Pugh class B. (A) On comparing the four groups with regard to changes in $\mathrm{NH}_{3}$, no significant changes were observed $(24.8 \pm 40.0, n=15$, carnitine $+\mathrm{BCAA}$; $-24.4 \pm 30.3, n=7$, carnitine-alone; $-25.0 \pm 45.2, n=15$, BCAA-alone; $-6.9 \pm 30.6, n=12$, non-dosed). (B) On comparing the four groups with regard to changes in Alb, no significant changes were observed $(0.31 \pm 0.36, n=15$, carnitine+BCAA; $-0.15 \pm 0.43, n=7$, carnitine-alone; $-0.10 \pm 0.46, n=15$, BCAA-alone; $0.03 \pm 0.45, n=12$, non-dosed). Alb, albumin; BCAA, branched-chain amino acid.

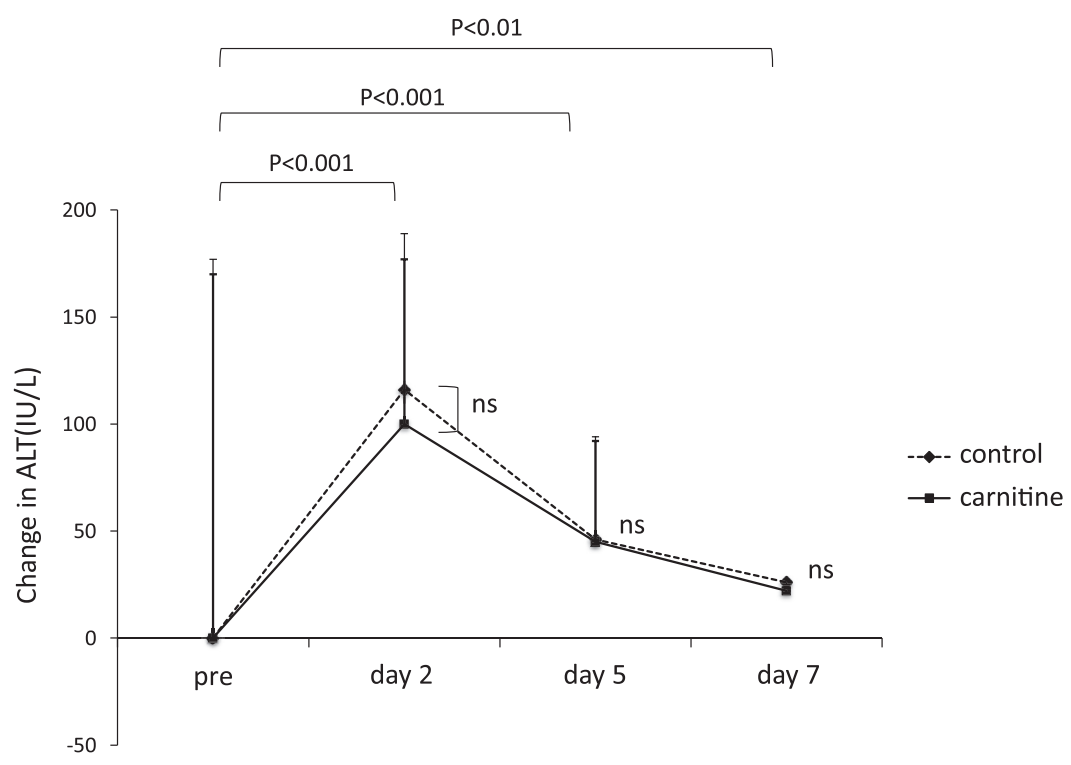

Supplementary Fig. 3. Chronological changes in serum ALT. The change in ALT (where 0 indicates the point prior to invasive treatment) was greatest on the second postoperative day $(100 \pm 170 \mathrm{IU} / \mathrm{L}, n=49$, carnitine; $116 \pm 177 \mathrm{IU} / \mathrm{L}, n=50$, control) and decreased significantly on postoperative days 5 ( $45 \pm 77 \mathrm{IU} / \mathrm{L}, n=49$, carnitine; $46 \pm 73 \mathrm{IU} / \mathrm{L}, n=50, \mathrm{control})$ and 7 (22 $477 \mathrm{IU} / \mathrm{L}, n=49$, carnitine; $26 \pm 48 \mathrm{IU} / \mathrm{L}, n=50$, control). No changes in ALT concentrations were seen when comparing the carnitine and control groups. ALT, alanine aminotransferase. 